\title{
Effect of intrauterine application of oestradiol-17 $\beta$ and prostaglandin E-2 on the porcine oestrous cycle and uterine endocrinology
}

\author{
J. P. Laforest* and G. J. King † \\ Department of Animal and Poultry Science, University of Guelph, Guelph, Ontario, \\ Canada NIG $2 \mathrm{Wl}$
}

\begin{abstract}
Summary. Silastic beads were inserted into the uterine lumen on Day 10 after oestrus. Gilts received beads containing oestradiol-17 $\beta$ only, oestradiol benzoate, or oestradiol$17 \beta+$ prostaglandin (PG) E-2. Oestrous cycles were slightly longer in treated than in untreated pigs $(20 \cdot 2 \pm 0.4$ days), and durations were $22.6 \pm 1 \cdot 3,26 \cdot 2 \pm 1 \cdot 7$ and $23.2 \pm 1.8$ days for oestradiol-17 $\beta$, oestradiol benzoate and oestradiol-17 $\beta$ + PGE-2 treatments, respectively $(P>0.05)$. Thus, PGE-2 and an oestrogen such as oestradiol benzoate that persist for a longer period cannot prolong the cycle more than oestradiol$17 \beta$ alone. Additional cyclic gilts underwent similar treatments with beads containing oestradiol-17 $\beta$, oestradiol-17 $\beta$ + PGE-2 or cholesterol, and cannulation of one uteroovarian vein on Day 10. Blood samples were collected from the catheter every $15 \mathrm{~min}$ from 08:00 until 11:00 $\mathrm{h}$ and from 20:00 until 23:00 h for 5 consecutive days starting the day after surgery and peripheral plasma samples were also collected daily. On Day 16, beads containing oestradiol-17 $\beta$ were surrounded by endometrial folds whereas cholesterol beads were free. Concentrations of plasma progesterone did not vary significantly from Days 11 to 16 in gilts treated with oestradiol-17 $\beta$ or oestradiol- $17 \beta+$ PGE-2, but decreased in cholesterol-treated gilts. Concentrations of plasma oestrone and oestradiol- $17 \beta$ were more than ten times higher in gilts treated with oestradiol-17 $\beta$ or oestradiol-17 $\beta+$ PGE-2 than in cholesterol-treated gilts on the day after bead insertion, but decreased rapidly to values comparable to those in cholesterol-treated gilts by Day 14. In contrast, concentrations of oestrone sulphate remained high until Day 16. Concentrations of PGE-2 in the utero-ovarian vein plasma did not differ $(P>0.05)$ between treatments but those of PGF-2 $\alpha$ were higher $(P<0.004)$ in gilts treated with cholesterol than in those treated with oestradiol-17 $\beta$ or oestradiol $-17 \beta+$ PGE-2. It is postulated that insufficient oestradiol-17 $\beta$ is released by the beads toward the end of a 'recognition period' to prolong the cycle for more than 3-6 days.
\end{abstract}

Keywords: oestradiol-17ß; prostaglandin E-2; luteolysis; oestrous cycle; pig

\section{Introduction}

Oestrogens, alone or perhaps in synergism with other compounds secreted by the pig blastocyst near the time of attachment, prevent luteolysis. Previous studies of the role of oestrogens in early pregnancy in pigs relied on parenteral injection (Gardner et al., 1963; Frank et al., 1977; Geisert et al., 1987) or uterine infusion (Ford et al., 1982), but pharmacological doses were usually administered. Silastic beads impregnated with oestradiol-17 $\beta$ and then placed in utero possibly represent an

*Present address: Département de Zootechnie, Université Laval, Sainte-Foy, Québec, Canada GIK 7P4.

$\dagger$ Reprint requests. 
alternative model which could provide near-physiological amounts by the natural route. Such beads provided new insight into the process of embryonic migration (Pope \& Stormshak, 1981; Pope et al., 1982) and on the influence of oestradiol-17 $\beta$ on uterine morphology (Keys, 1987; Keys \& King, 1988, 1990) and the utero-ovarian relationship (Keys, 1987; King \& Rajamahendran, 1988).

In contrast to injections of oestrogens, beads of oestradiol-17 $\beta$ extended cycle length, but failed to cause the full transition to pseudopregnancy in most treated pigs (King \& Rajamahendran, 1988), suggesting that the effect of near-physiological and pharmacological doses of oestrogens can be quite different. Embryos secrete compounds other than oestrogens in the peri-attachment period, including proteins (Godkin et al., 1982) and prostaglandins (Lewis, 1989), that can complement the actions of oestrogen. Prostaglandin (PG) E-2 delayed luteolysis in ewes (Henderson et al., 1977; Pratt et al., 1977, 1979) and cows (Reynolds et al., 1983), some results suggesting a similar action in pigs (Schneider et al., 1982, 1983; Akinlosotu et al., 1986).

Experiments were conducted on the role of oestrogens in early pregnancy and the possible involvement of PGE-2. It was postulated that the inability of oestradiol-17 $\beta$ beads alone to initiate prolonged pseudopregnancy came either from a rapid clearance of oestradiol-17 $\beta$ from the circulation or from the absence of an antiluteolytic agent. Oestradiol benzoate, an oestrogenic compound that persists in the circulation for much longer than oestradiol-173, was used to determine whether intrauterine administration of small amounts would prevent luteolysis; PGE-2 was included with oestradiol- $17 \beta$ to determine whether this would facilitate luteal function.

\section{Materials and Methods}

\section{Animals and management}

Sexually mature Yorkshire gilts of similar age ( $\sim 250$ days old) and weight $(90-120 \mathrm{~kg}$ ) were housed in a $3 \mathrm{~m} \times$ $3.7 \mathrm{~m}\left(11.1 \mathrm{~m}^{2}\right)$ pen $(8.12$ gilts/pen) and floor fed $2.5 \mathrm{~kg} /$ animal per day a $15 \%$ crude protein diet (maize and soyabean). Water was always available from drinking nipples. The gilts were checked daily for oestrus with a boar and they were considered ready for experimentation after at least two oestrous cycles of normal length (19-22 days). After assignment into experimental groups, the first day of standing oestrus for each gilt was considered as Day 0 .

\section{Preparation of beads}

Silastic beads were prepared by the method of Pope et al. (1982) with some modifications. A paste of Silastic glue $(3 \mathrm{ml} ; 1.5 \mathrm{~g} / \mathrm{ml}$; Dow Corning Corp., Corning, NY, USA) was mixed with $2 \mathrm{~g}$ of oestradiol- $17 \beta, 2 \mathrm{~g}$ of oestradiol benzoate, $2 \mathrm{~g}$ of oestradiol-17 $+10 \mathrm{mg}$ of PGE-2 or $2 \mathrm{~g}$ of cholesterol (all from Sigma Chemical Co., St Louis, MO, USA) with a small volume of diethyl ether as a solvent. After drying for $0.5 \mathrm{~h}$, the slurry was placed into a syringe and extruded into long ridges from which beads with a diameter of $\approx 2 \mathrm{~mm}$ were formed by hand. The beads for oestradiol$17 \beta$, oestradiol benzoate, oestradiol-17 $\beta+$ PGE-2 and cholesterol weighed (mean \pm SEM) $190 \pm 3 \cdot 1,219 \pm 2 \cdot 1,199 \pm$ $1 \cdot 6.22 \mathrm{l} \pm 3.0 \mathrm{mg} / 10$ beads, respectively. The calculated hormonal content of the beads was $\approx 65 \mathrm{mg}$ of oestrogens or cholesterol/10 beads and $300 \mathrm{mg}$ of PGE-2/10 beads.

Two days before surgery, beads were incubated at $4^{\circ} \mathrm{C}$ for $24 \mathrm{~h} \mathrm{in} 5 \mathrm{ml}$ of plasma from castrated males, rinsed three times with Dulbecco's phosphate-buffered saline ( $\mathrm{pH} 7 \cdot 4$; Gibco Laboratories, Grand Island, NY, USA) and blotted dry. The oestradiol- $17 \beta$, oestradiol benzoate and cholesterol beads were autoclaved at $121^{\circ} \mathrm{C}$ for $35 \mathrm{~min}$ before insertion into the uterus, whereas the oestradiol- $17 \beta+$ PGE-2 beads were kept for $10 \mathrm{~min}$ in a $70 \%$ ethanol solution and washed three times in bacteriostatic water immediately before uterine insertion.

\section{Experiment 1}

Fifteen gilts were assigned randomly to receive Silastic beads containing either oestradiol-17 $\beta$, oestradiol benzoate or oestradiol-17 $\beta$ + PGE-2. On Day 10 of the cycle, anaesthesia was induced with methohexitone and maintained by a mixture of halothane, nitrous oxide and oxygen. Beads were introduced into the uterine lumen of all the animais by midventral laparotomy. Two incisions were made in each horn, one at the tip and the other near the middle of the horn, and five beads were introduced into the uterine lumen through each incision. At the conclusion of surgery, a polyvinyl catheter (Dural Plastic and Engineering. Dural, Australia; $1.2 \mathrm{~m}$ long; internal diameter 0.80 mm; external diameter $1.20 \mathrm{~mm}$ ) was passed into the anterior vena cava via the ear vein. Heparin (200 iu in $0.15 \mathrm{~mol}$ saline/l) was injected into the catheter and replaced after each subsequent sampling to prevent blood clotting. Antibiotics and 
analgesic were administered for several days after surgery. This surgical procedure has been frequently used in our laboratories and shown not to extend cycle length per se.

Peripheral plasma samples were obtained 3 days before, one day before and on the day of surgery. After surgery, daily plasma samples were taken from the catheter. Plasma samples were frozen at $-20^{\circ} \mathrm{C}$ until assayed for progesterone. Gilts were kept in gestation crates and checked daily in the presence of a boar for any sign of oestrous behaviour. For an additional comparison among treatments, the fifth day of plasma progesterone concentrations $<1 \mathrm{ng} / \mathrm{ml}$ was also chosen as the end of one and the beginning of a subsequent cycle, as the preovulatory surge in luteinizing hormone occurs $\approx 5$ days after the rapid drop in peripheral progesterone (Henricks et al., 1972; Parvizi et al., 1976). All the gilts were slaughtered on Day 30 and the genital tracts were examined to determine reproductive status, giving particular attention to the appearance of the corpora lutea and location of the beads. Only gilts with peripheral progesterone concentrations $>1 \mathrm{ng} / \mathrm{ml}$ until slaughter day were considered pseudopregnant.

\section{Experiment 2}

Twelve gilts underwent midventral laparotomy on Day 10 of the cycle and received one of the following types of beads: impregnated with cholesterol, impregnated with oestradiol-17 $\beta$, or impregnated with oestradiol-17 $\beta$ + PGE- 2 . Beads were inserted into the uterine lumen as described in Expt 1. A large utero-ovarian vein from one horn was cannulated near the ovary with a polyvinyl catheter (described in Expt 1). The catheter was exteriorized through the flank, filled with heparin solution and contained in a plastic bag taped on the back of the gilt between collection periods.

Peripheral plasma samples were obtained on Day 3 and Day 1 before surgery, on the day of surgery and for the next 6 days. Blood samples were collected from the utero-ovarian vein starting from the morning after surgery, immediately centrifuged for $30 \mathrm{~min}$ at $3000 \mathrm{~g}$ at $4^{\circ} \mathrm{C}$, and plasma was collected, frozen and stored at $-20^{\circ} \mathrm{C}$. Twentysix samples were collected daily, at intervals of $15 \mathrm{~min}$, from 08:00 until 11:00 h and from 20:00 until 23:00 h, for 5 complete days. On the sixth day, the gilts were transported to the abattoir, where a blood sample was collected from the catheter just before slaughtering. All samples from the utero-ovarian vein were assayed for PGF-2 $\alpha$ and PGE-2. A pool of all catheter samples for the same animal on the same day was prepared and assayed for oestrone, oestradiol$17 \beta$, total oestrone (oestrone + oestrone sulphate) and progesterone. The peripheral blood samples were assayed for oestradiol-17 $\beta$, total oestrone and progesterone.

The uteri were taken to the laboratory within $10 \mathrm{~min}$. Both uterine horns were dissected from the mesometrium and one was flushed with $20 \mathrm{ml}$ of phosphate-buffered saline ( $\mathrm{pH} \mathrm{7.4).} \mathrm{Both} \mathrm{horns} \mathrm{were} \mathrm{cut} \mathrm{open} \mathrm{longitudinally} \mathrm{and}$ pinned on a large dissecting tray with the endometrium side up. The distribution of the beads within the uterine horns was recorded.

\section{Hormone assays}

Previously validated radioimmunoassays were used for the measurement of oestrone, total oestrone, oestradiol173, progesterone, PGF-2 $\alpha$ and PGE-2. For all the hormonal assays, reported values were corrected according to extraction efficiency.

Progesterone. Assays were performed as described by King et al. (1985), using plasma samples of $50 \mu$. The extraction efficiency was $85.2 \%$, the assay sensitivity was $140 \mathrm{pg} /$ assay tube and the intra- and interassay coefficients of variation $(\mathrm{CV})$ were 5.9 and $16.1 \%$, respectively.

Oestrogens. Oestradiol-17 $\beta$ was assayed as described by Guilbault et al. (1988), using $500 \mu 1$ of plasma. The extraction efficiency was $92 \cdot 1 \%$, the assay sensitivity was $7.0 \mathrm{pg} /$ assay tube and the intra- and interassay CV were 8.2 and $9 \cdot 2 \%$, respectively. Oestrone and oestrone sulphate were assayed as described by Raeside \& Rosskopf (1980), using $100 \mu \mathrm{l}$ of plasma. Since the antiserum used had the same affinity for oestrone and oestrone sulphate, the assay done without extraction gave a combined value for both hormones (total oestrone $=$ oestrone + oestrone sulphate). The assay sensitivity for total oestrone was $3.0 \mathrm{pg} /$ assay tube and the intra- and interassay $\mathrm{CV}$ were 5.8 and $8.4 \%$, respectively. The extraction efficiency for oestrone was $90.5 \%$, the assay sensitivity was $2.0 \mathrm{pg}$ and the intra- and interassay $\mathrm{CV}$ were 5.8 and $9.9 \%$, respectively. Oestrone sulphate alone was obtained by the difference between total oestrone and oestrone. Negative calculated oestrone sulphate values were considered to be zero.

Prostaglandins. PGF- $2 \alpha$ and PGE-2 were asayed as described by Kennedy (1979), using $200 \mu$ l of plasma; extraction efficiencies were 95.6 and $85.0 \%$, respectively. For PGF- $2 \alpha$ assay, the sensitivity was $60 \mathrm{pg} /$ assay tube and the intra- and interassay CV were 8.4 and $13.3 \%$, respectively. For PGE-2 assay, the sensitivity was $40 \mathrm{pg} /$ assay tube and the intra- and interassay $\mathrm{CV}$ were 3.3 and $13.8 \%$, respectively.

\section{Statistical analyses}

Unless otherwise specified, all the data were analysed using the SAS GLM procedure (SAS, 1987). Whenever variation is reported it is always the standard error of the mean (SEM).

Results from Expt 1 were analysed as a split-plot design (repeated measurements on the same animal) with the treatments as the main plots and the days as the subplots (Snedecor \& Cochran, 1980). The variance in between treatments was homogeneous as assessed by a Burr-Foster's test (Anderson \& McLean, 1974). The treatment effect 
was further subdivided using non-orthogonal contrasts (oestradiol-17 $\beta$ vs. oestradiol benzoate; oestradiol-17 $\beta$ vs. oestradiol-17 $\beta+$ PGE-2). The analysis was done only on samples taken after bead insertion (Days 11-30).

In Expt 2, all hormones measured in utero-ovarian and peripheral plasma, except for PGE-2 and PGF-2 $\alpha$, were analysed as a split-plot design, with treatments as main plots and days of sampling as subplots. The treatment effect was further divided by orthogonal contrasts (cholesterol vs. oestradiol-17 $\beta$ and oestradiol-17 + PGE-2; oestradiol$17 \beta$ vs. oestradiol-17 $\beta+$ PGE-2) and trend comparisons were used to study the effect of days (Little \& Hills, 1978). Only peripheral plasma samples taken after insertion of the beads were analysed (Days 11-16). A natural logarithm transformation was used for oestradiol- $17 \beta$ values in both peripheral and utero-ovarian vein plasmas, whereas a square-root transformation was used for total oestrone in the peripheral plasma and oestrone in the utero ovarian vein plasma, but original data means are reported.

Data on PGE-2 and PGF-2 $\alpha$ from the utero-ovarian vein plasma were analysed as a split-split-plot design, with treatments as main plots, days as subplots, and sampling periods (mornings vs. evenings) as sub-subplots. Orthogonal comparisons (cholesterol vs. oestradiol-17 $\beta$ and oestradiol-17 + PGE-2; oestradiol-17 $\beta$ vs. oestradiol-17 $\beta+$ PGE2) were used to study the effect of treatments. Variance was heterogeneous among treatments, as assessed by a BurrFoster's test, but an adequate transformation could not be obtained from the procedure described by Montgomery (1984). However, a natural logarithm considerably reduced non-homogeneity, so the data were transformed before analysis, but original data means are reported and the actual data were also used for the spike analysis.

Secretory spikes were identified for both prostaglandins using a method outlined by Christian et al. (1978). The method consisted of separating the data for each pig into two 'subpopulations'. Most values belonged to a normally distributed 'inlier' population, the others forming an 'outlier' population of peak values. Analysis of variance of the inliers was done after a natural logarithm transformation, but original data means are reported.

\section{Results}

\section{Experiment 1}

Concentration of progesterone in plasma varied substantially, even within the same treatment (Fig. 1). A considerable proportion of this variation probably resulted from transient cycle prolongation in some individuals for each treatment. This ranged from an extension of the cycle for several days in some gilts, to no apparent prolongation in others. For all treatments, a decline followed by an increase in plasma progesterone concentrations was observed, in accordance with dynamics of corpora lutea function normally occurring at the end of a cycle and the beginning of the following cycle (between Days 10 and 30 after oestrus; Fig. 1). This corresponded statistically to a very strong day effect $(P<0.001)$. There seemed to be a delay before the rapid drop in plasma progesterone concentrations in gilts treated with oestradiol benzoate compared with the other two treatments (Fig. 1). A treatment effect was found $(P<0.04)$ that was not associated with the nonorthogonal comparisons chosen a priori (oestradiol-17 $\beta$ vs. oestradiol-17 $\beta+$ PGE-2 and oestradiol- $17 \beta$ vs. oestradiol benzoate).

Plasma progesterone concentrations $>15 \mathrm{ng} / \mathrm{ml}$ were maintained for 3 and 5 more days with treatment with oestradiol benzoate than with oestradiol-17 $\beta$ or oestradiol-17 $\beta+$ PGE-2, respectively. The average duration of oestrous cycles before and after the experiment were, respectively, oestradiol- $17 \beta$ gilts, $20 \cdot 4 \pm 0.4$ and $22.5 \pm 1 \cdot 3$ days; oestradiol benzoate gilts, $20 \cdot 2 \pm 0 \cdot 4$ and $25.0 \pm 1.7$ days; and oestradiol-17 $\beta+$ PGE- 2 gilts, $20.2 \pm 0.5$ and $22.3 \pm 1.9$ days. In all but two gilts, cycles were longer after bead treatments than before, but, in many cases, this difference was only 1 or 2 days. Behavioural signs of oestrus were not recorded in one gilt treated with oestradiol$17 \beta$ and one with oestradiol-17 $\beta+$ PGE-2, so these females were not included in the calculation of the average cycle length. For a possibly more objective comparison of cycle length among all gilts, plasma progesterone profiles were used, with cycle end defined as the fifth day of progesterone values $<1 \mathrm{ng} / \mathrm{ml}$. With this criterion, the oestrous cycle of gilts treated with oestradiol benzoate appeared to be slightly longer than that of gilts treated with oestradiol-17 $\beta$ or oestradiol-17 $\beta+$ PGE-2 $(26.2 \pm 1 \cdot 7,22.6 \pm 1 \cdot 3$ and $23.2 \pm 1.8$ days, respectively) and three gilts treated with oestradiol benzoate showed cycles longer than any other animal in this experiment (27, 28 and 31 days). However, differences between effects of treatment with oestradiol benzoate and oestradiol-17 $\beta$ were not statistically significant $(P>0 \cdot 10)$. All bead treatments may have prolonged the cycle by a few days in at least some of the treated gilts, but none induced prolonged pseudopregnancy. 


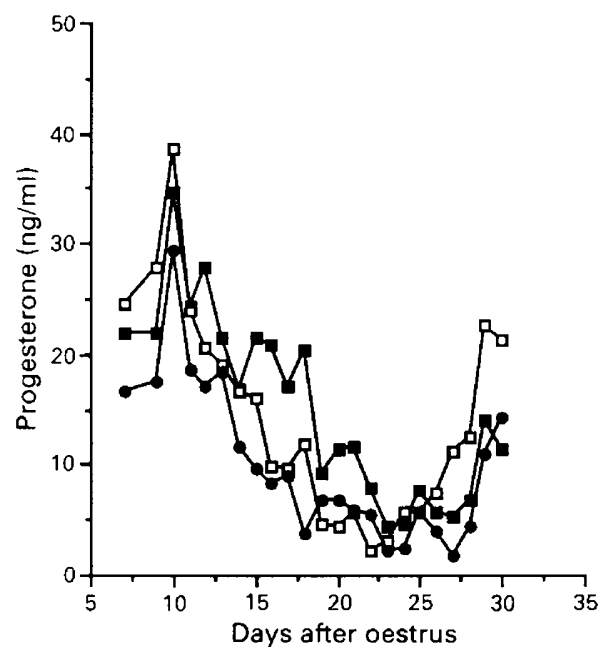

Fig. 1. Mean progesterone concentrations in peripheral plasma of gilts treated with Silastic beads containing oestradiol benzoate $(\boldsymbol{\square})$, oestradiol-17 $(\square)$ or oestradiol-17 $\beta$ + prostaglandin E-2 (O) and inserted in the uterine lumen by midventral laparotomy on Day 10 after oestrus $(\mathrm{SEM} \pm 3.5 \mathrm{ng} / \mathrm{ml}$ ).

\section{Experiment 2}

Gilts treated with beads containing oestradiol-17 $\beta$ had well vascularized corpora lutea on Day 16, compared with the small and pale corpora lutea of gilts that received cholesterol beads. In general, the uteri of gilts treated with beads containing oestradiol-17 $\beta$ were more turgid and paler than those of gilts treated with cholesterol beads. Oestradiol-17 $\beta$ and oestradiol- $17 \beta+$ PGE- 2 gilts had significantly longer uterine horns $(P<0.05)$ than cholesterol-treated gilts $(128 \pm 7,125 \pm 9$ and $100 \pm 7 \mathrm{~cm}$, respectively). Between Days 10 and 16, beads moved down the uterine horns in all gilts (Fig. 2). Cholesterol beads were free inside the uterine lumen and many were removed when the uterine horn was flushed ( 27 out of 40 beads). In contrast, oestradiol-17 $\beta$ and oestradiol-17 $\beta+$ PGE-2 beads were more evenly spaced and difficult to dislodge; only seven out of 40 oestradiol-17 $\beta$ beads and four out of 40 oestradiol-17 $\beta+$ PGE-2 beads were found in uterine flushings. Examination of the relationship between beads and uterine mucosa showed that oestradiol-17 $\beta$ and oestradiol-17 $\beta$ + PGE-2 beads were tightly 'embedded' in epithelial folds, but cholesterol beads rested on the surface. There was no obvious difference in the spacing of the beads between treatments with oestradiol-17 $\beta$ and oestradiol-17 $\beta$ + PGE-2.

Progesterone. Progesterone concentrations were higher in the utero-ovarian vein plasma than in the peripheral plasma $(15-80 \mathrm{ng} / \mathrm{ml}$ and $7-30 \mathrm{ng} / \mathrm{ml}$, respectively). Analysis of variance indicated that neither treatments nor days affected peripheral progesterone concentrations $(P>0 \cdot 10)$. Progesterone concentrations of $\approx 15 \mathrm{ng} / \mathrm{ml}$ obtained on Day 11 were maintained until Day 16, except for cholesterol-treated gilts, in which they dropped to $<10 \mathrm{ng} / \mathrm{ml}$ after Day 14 (Fig. 3). This peculiarity of the cholesterol treatment was confirmed by an analysis of the slopes of linear equations representing peripheral plasma progesterone concentrations as a function of days for each treatment. These slopes were not different from zero for oestradiol-17 $\beta$ and oestradiol$17 \beta+$ PGE-2 treatments, but presented a significant negative slope for cholesterol-treated gilts.

In utero-ovarian vein plasma, an effect $(P<0.05)$ of oestradiol-17 $\beta$ and oestradiol$17 \beta+$ PGE-2 vs. cholesterol treatments was obtained, as well as significant linear and quadratic trends. Slightly higher progesterone concentrations on Days 12 and 13 explain the quadratic trend. Progesterone concentrations in the utero-ovarian vein plasma started declining earlier and faster in cholesterol-treated gilts than in the other treatments (Fig. 4). Slopes of linear equations 

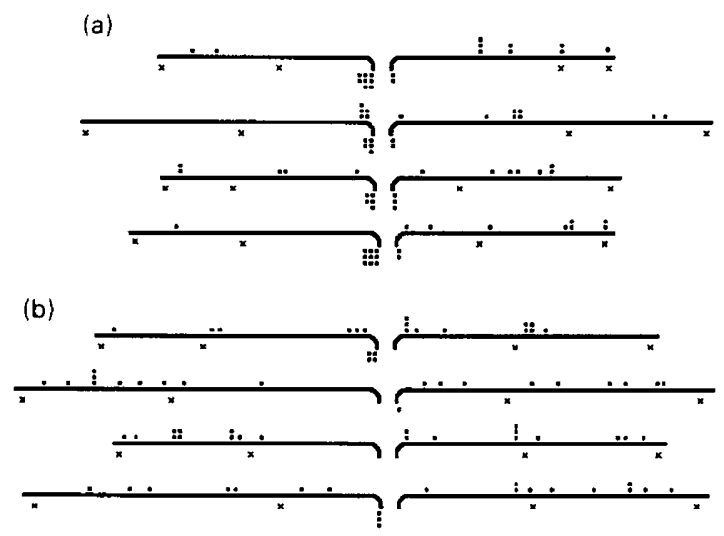

(c)

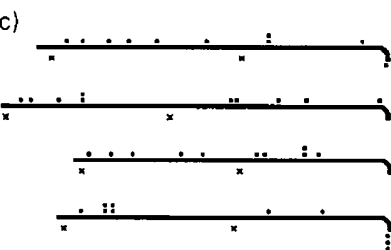

Flushed

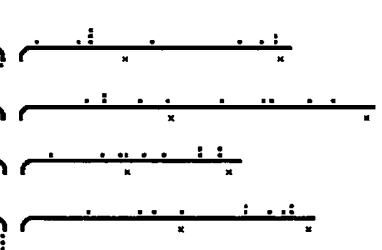

Unflushed

$50 \mathrm{~cm}$

Fig. 2. Representation of the position of Silastic beads ( $)$ inside the uterine horns $(-)$ of gilts slaughtered on Day 16 after oestrus. Cervical ends are near the centre of the figure and bent downward. Left horns were flushed with $20 \mathrm{ml}$ Dulbecco's phosphate-buffered saline prior to opening and measurements. Beads containing either (a) cholesterol, (b) oestradiol-17 $\beta$ or (c) oestradiol-17 $\beta$ + prostaglandin E-2 were inserted into the uterine lumen by midventral laparotomy on Day 10 after oestrus; $x$ represents bead insertion points (two per horn) and dots below the bent part of the horns represent beads that were either in the cervix or in uterine flushings.

representing utero-ovarian plasma progesterone concentrations as a function of days were significantly different from zero and negative only for cholesterol treatment. They also indicated that the decrease in plasma progesterone concentrations of cholesterol-treated gilts occurred faster in the utero-ovarian vein than in the peripheral plasma.

Oestrogens. Concentrations of oestradiol- $17 \beta$ were, on average, $\approx 10-15 \mathrm{pg} / \mathrm{ml}$ in the peripheral plasma and $\approx 20-25 \mathrm{pg} / \mathrm{ml}$ in the utero-ovarian vein plasma in cholesterol-treated gilts. Concentrations of total oestrone and of oestrone in plasma in such gilts were approximately twice as high as oestradiol-17 $\beta$ concentrations. Cholesterol-treated gilts presented low oestrogen concentrations in both peripheral and utero-ovarian vein plasmas throughout the experimental period; slopes of linear equations representing plasma oestrogen concentrations as a function of days were not different from zero.

For groups treated with beads containing oestradiol-17 $\beta$, the presurgical peripheral plasma oestrogen values were comparable to those of cholesterol-treated gilts. On the day after bead insertion, a more than tenfold increase in oestradiol-17 $\beta$ and total oestrone concentrations was observed in the peripheral plasma (Fig. 3). This dramatic rise clearly resulted in a significant effect of treatments for cholesterol vs. oestradiol-17 $\beta$ and oestradiol-17 $\beta+$ PGE-2 gilts $(P<0 \cdot 001)$. Concentrations of oestradiol-17 $\beta$ in the peripheral plasma were slightly higher $(P<0.07)$ for oestradiol-17 $\beta$ than for oestradiol-17 $\beta+$ PGE-2 treatments, whereas total oestrone $(P<0.03)$ and especially oestrone concentrations $(P<0.001)$ in the utero-ovarian plasma were higher in oestradiol-17 $\beta$ than in oestradiol-17 $\beta+$ PGE-2 treatments. Oestrone sulphate concentrations did 

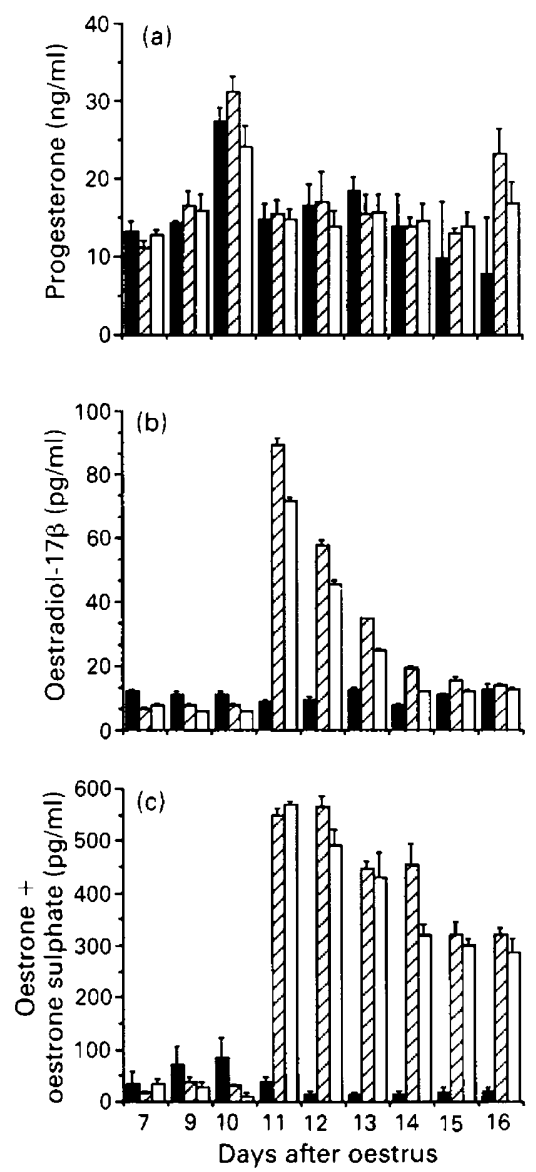

Fig. 3. Concentrations of hormones (mean \pm SEM) in peripheral plasma of gilts treated with Silastic beads containing cholesterol $(\mathbb{Q})$, oestradiol-17 $(\mathbb{Z})$ or oestradiol-17\% + prostaglandin E-2 $(\square)$ inserted in the uterine lumen by midventral laparotomy on Day 10 after oestrus.

not differ significantly between oestradiol-17\% and oestradiol-17 $\beta+$ PGE-2 gilts, although oestradiol-17 $\beta+$ PGE-2 gilts showed a tendency for higher oestrone sulphate concentrations for every day of the experiment except Day 16.

After the post-surgical surge, oestradiol-17 $\beta$ concentrations in peripheral plasma of oestradiol$17 \beta$ and oestradiol-17 + PGE-2 gilts dropped rapidly to reach values comparable to those in cholesterol-treated gilts by Day 15 . The decline in oestradiol-17 $\beta$ concentrations in utero-ovarian vein plasma was faster than in peripheral plasma. Oestradiol- $17 \beta$ in the utero-ovarian vein plasma seemed to decrease faster in oestradiol-17 $\beta+$ PGE- 2 than in oestradiol-17 $\beta$ treatments. This observation is supported by a significant difference $(P<0.05)$ in the slopes of linear equations describing the hormonal changes over time.

Contrary to what was observed with oestradiol- $17 \beta$, total oestrone concentrations in peripheral plasma and both total oestrone and oestrone sulphate concentrations in utero ovarian vein plasma remained high until Day 16 in oestradiol-17 $\beta$ and oestradiol-17 $\beta+$ PGE-2 gilts, with only a slight decrease over time (Figs 3 and 4). Total oestrone concentrations decreased in a similar way $(P<0.05)$ for both oestradiol-17 $\beta$ and oestradiol-17 $\beta+$ PGE-2 treatments in the peripheral plasma, whereas the decrease was faster for oestradiol-17 $\beta$ vs. oestradiol-17 $\beta+$ PGE-2 gilts in utero-ovarian vein plasma. Oestrone concentrations in utero-ovarian vein plasma declined rapidly 

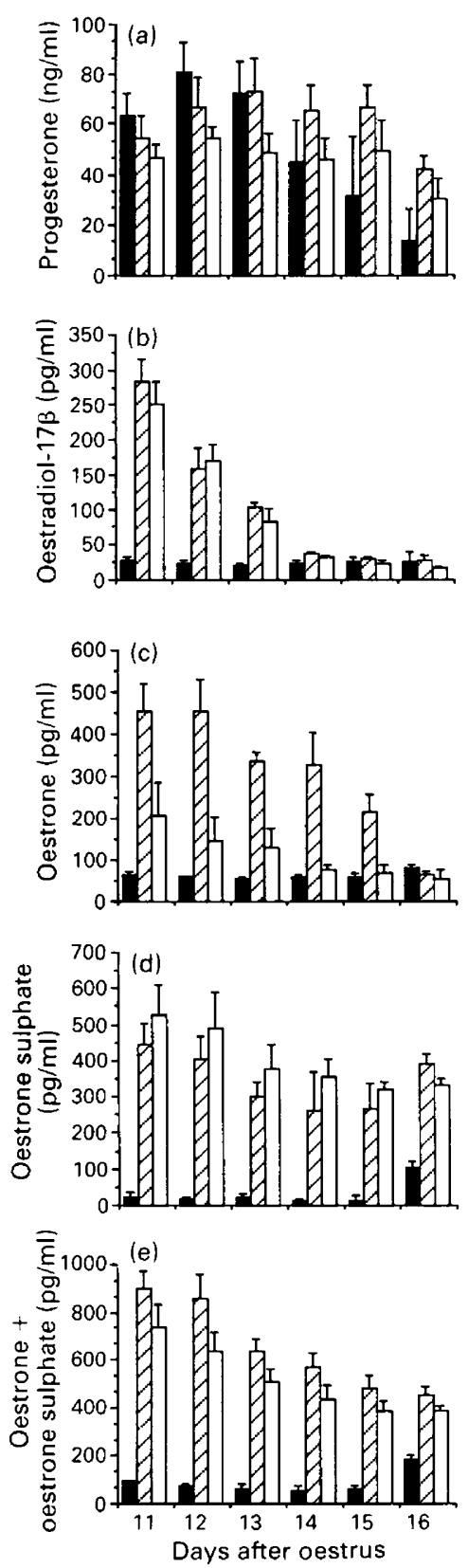

Fig. 4. Concentrations of hormones (mean \pm s.e.m.) in utero-ovarian vein plasma of gilts treated with Silastic beads containing cholesterol $(\mathbf{\square})$, oestradiol-17ß $(\mathbb{Z})$ or oestradiol$17 \beta+$ prostaglandin E-2 $(\square)$ inserted in the uterine lumen by midventral laparotomy on Day 10 after oestrus.

in oestradiol-17 $\beta$ and oestradiol-17 $\beta+$ PGE-2 gilts. Oestrone concentrations were significantly $(P<0.01)$ lower in oestradiol-17 $\beta+$ PGE-2 than in oestradiol-17 $\beta$ gilts throughout the experimental period, except on Day 16 when oestradiol- $17 \beta$ and oestradiol-17 $\beta+$ PGE-2 treatments gave oestrone values similar to cholesterol treatment. Oestrone was the only hormone measured for which oestradiol-17 $\beta$ and oestradiol-17 $\beta+$ PGE-2 gilts differed consistently. 
Prostaglandins. Overall, PGF-2 $\alpha$ concentrations were higher $(P<0.004)$ in cholesteroltreated gilts than in other treatments, whereas no effect $(P<0.05)$ of treatments was observed for PGE-2 concentrations (Table 1). Similar results were obtained with inlier values (data not shown). Neither days nor sampling periods (mornings vs. evenings) affected plasma concentrations of either prostaglandin $(P>0 \cdot 10)$; but a significant $(P<0.01)$ interaction was found between days and periods of sampling for PGE-2 concentrations, which were higher during the evenings on Days 1 and 4, but lower on Day 2, and did not seem to differ between periods on Days 3 and 5. The interaction probably resulted from an effect of high secretory spikes, in particular a large spike occurring on the morning of Day 2 in one of the cholesterol-treated gilts, as the level of significance of the interaction was reduced $(P<0.05)$ when only the inlier data were considered.

Hormonal profiles were extremely variable between gilts, even within the same treatment, for both PGF-2 $\alpha$ and PGE-2. The average number of secretory spikes for PGF-2 $\alpha$ and PGE-2, respectively, were: $3.8 \pm 1.0$ and $3.3 \pm 1.7$ for cholesterol treatment, $2.8 \pm 1.4$ and $2.0 \pm 1.3$ for oestradiol- $17 \beta$ treatment and $2 \cdot 2 \pm 1.9$ and $3.3 \pm 1.3$ for oestradiol-17 $\beta+$ PGE-2 treatment. The differences between treatments were not significant $(P>0 \cdot 10)$. The amplitude of the secretory spikes for each gilt varied on average from $2 \cdot 0 \pm 0 \cdot 2$ to $12 \cdot 5 \pm 0 \cdot 0 \mathrm{ng} / \mathrm{ml}$ for PGF- $2 \alpha$ and $173 \pm 6$ to $1154 \pm 0 \mathrm{pg} / \mathrm{ml}$ for PGE-2.

\section{Discussion}

Intrauterine insertion of Silastic beads containing oestradiol-17 $\beta$ slightly prolonged the oestrous cycle in some of the treated gilts, but failed to cause pseudopregnancy in any of the animals studied. These results conflict with the response obtained to parenteral administration of oestrogens (Gardner et al., 1963; Frank et al., 1977; Guthrie \& Rexroad, 1981; Ziecik et al., 1986; Geisert et al., 1987), but are in accordance with previous studies in which similar Silastic beads were used (Keys, 1987; King \& Rajamahendran, 1988). Administration of exogenous oestrogen is necessary between Days 11 and 15 of the oestrous cycle to prolong luteal function in pigs (Kidder et al., 1955; Gardner et al., 1963; Frank et al., 1977; Geisert et al., 1987), indicating a restricted 'recognition period' during which high oestrogen concentrations in peripheral plasma are necessary to obtain pseudopregnancy in gilts. Beads incubated in phosphate-buffered saline for 20 days presented a dramatic and unexplained decrease in oestradiol- $17 \beta$ release rate starting on the fourth day of incubation (data not shown). With Silastic beads, the oestradiol-17 $\beta$ signal at the beginning of the recognition period therefore initiates some changes that lengthen the cycle, but this is not sufficient to maintain an extended pseudopregnancy.

It was hypothesized that impregnating beads with an oestrogen such as oestradiol benzoate, which persists for longer than oestradiol-17 $\beta$, would maintain concentrations for a sufficient period to complete the changes necessary for establishment of pseudopregnancy. This was not confirmed, but oestradiol benzoate beads did delay the decline in peripheral plasma progesterone for slightly longer than oestradiol-17 $\beta$ beads, suggesting that the response of the corpora lutea and/or the uterus to peripheral plasma oestrogens may be partly dose dependent. In an unreported preliminary trial, three out of four gilts that received larger Silastic beads containing more oestradiol-17 $\beta$ per unit of weight successfully maintained peripheral progesterone concentrations $>15 \mathrm{ng} / \mathrm{ml}$ until Day 30 after oestrus. Both size and oestradiol-17 $\beta$ content of the beads were reduced in the present experiment in an attempt to release a near-physiological amount of oestrogen, because of the observation that more oestradiol-17 $\beta$ was found in uterine fluid after treatment with larger beads than is found in pregnant gilts (Keys, 1987).

Addition of PGE-2 to oestradiol- $17 \beta$ in the beads also failed to prolong cycles beyond the length obtained with beads containing oestradiol-17 $\beta$ alone. These results do not support the observation that intrauterine administration of PGE-2 via a catheter can prolong cycles in pigs 


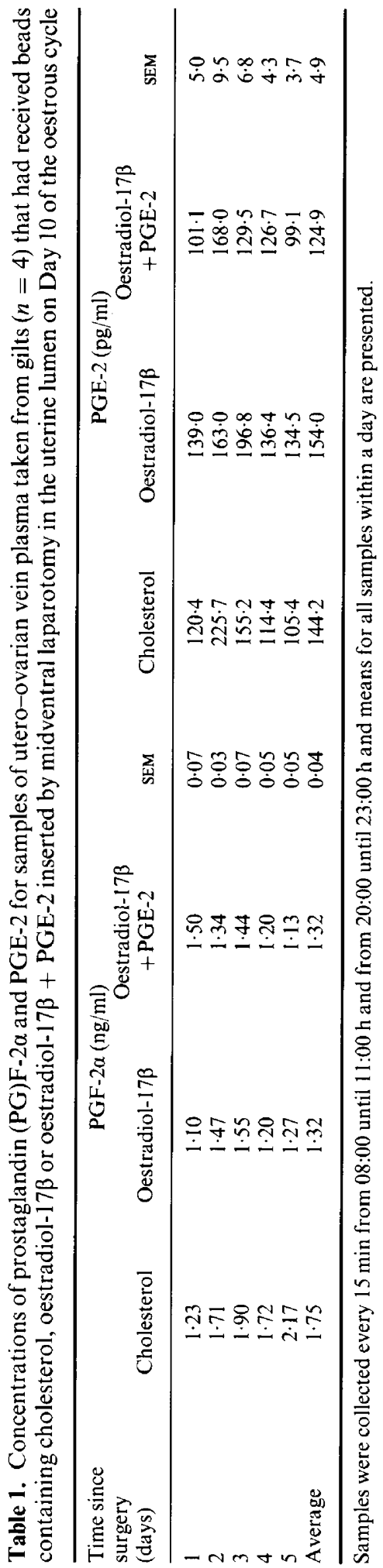


(Akinlosotu et al., 1986), unless the effect is not additive to an effect of oestradiol-17 PGE-2 alone could not be evaluated, because beads containing cholesterol and PGE-2 were not retained inside the uterine horns (data not shown). In previous experiments in ewes (Pratt et al., 1977, 1979), cows (Reynolds et al., 1983) and sows (Schneider et al., 1982, 1983; Akinlosotu et al., 1986), cycle lengthening was obtained with infusions of $\approx 1000 \mu \mathrm{g}$ PGE-2/day into the uterine lumen. The sparing effect of intrauterine administration of PGE-2 on the corpora lutea was also found with indomethacin-treated gilts in which PGE-2 neutralized the luteolytic effect of simultaneously infused PGF-2 $\alpha$ (Akinlosotu et al., 1988). In all previously mentioned experiments, the quantities of PGE-2 used seem above physiological values. Sheep and cow blastocysts release $\approx 20 \mathrm{ng}$ of PGE-2/mg of wet weight in $24 \mathrm{~h}$ in vitro (Lewis, 1989), and pig blastocysts that metabolize arachidonic acid into PGE-2 in vitro (Lewis \& Waterman, 1983; Lewis, 1989) could produce $\approx 18-20 \mu \mathrm{g}$ of $\mathrm{PGE}-2 /$ horn per day, at the time when luteolysis must be inhibited in pregnant animals, assuming a similar release rate in vitro for pig, sheep and cow blastocysts and assuming that this release rate is the same in vivo as in vitro. These values represent only $1 \%$ of what was infused into the horn in most studies, demonstrating an anti-luteolytic effect of PGE-2, but are similar to the average amount released in vitro by the beads used in the present study (data not shown).

The second experiment was conducted to investigate more precisely the effect of the Silastic beads on uterine physiology. Uteri of gilts treated with beads containing oestradiol-17 $\beta$ were more turgid and paler than those of cholesterol-treated gilts. Uterine horns were also longer. Perry \& Rowlands (1962) observed that the uterus elongates rapidly during the first 18 days after mating, suggesting an effect of embryonic oestrogens. These results were not confirmed by Wu et al. (1988), who found that gravid and nongravid horns are of the same length in the same animal, until Day 18 of gestation. However, embryonic oestrogens from the gravid horn could probably reach the nongravid horn, explaining the similarity in length of both horns. Indeed, a systemic effect of ovarian oestrogens on uterine growth around puberty has been demonstrated with unilaterally ovariectomized gilts (Wu \& Dziuk, 1988). A role for oestrogens of intrauterine origin in increasing porcine uterine length in early pregnancy is supported by the results of the present experiment.

Most of the beads moved down the uterine horns of all the gilts, regardless of treatments. Beads were spaced more or less evenly inside the horn although groups of two or three beads were also seen. Cholesterol beads were always loose inside the uterine lumen whereas beads with oestradiol$17 \beta$ always initiated a folding reaction of the endometrium resulting in the beads being surrounded by epithelial folds. This reaction was observed by Keys \& King (in press), but was not reported by Pope et al. (1982). Since the movement of the blastocyst stops at about Day 12 (Dziuk, 1985) when the blastocyst begins elongation (Geisert et al., 1982) and membrane apposition (Keys \& King, 1990), it is likely that slaughter in the experiment of Pope et al. (1982) occurred just before the folding process.

Beads containing oestradiol- $17 \beta$ modified the secretion and/or release of progesterone and PGF-2 $\alpha$. Progesterone concentrations obtained in peripheral and utero-ovarian vein plasmas were comparable to values from previous studies with cycling gilts in the luteal phase (Stabenfeldt $e t$ al., 1969; Henricks et al., 1972), gilts in early pregnancy (Guthrie et al., 1972; Ash \& Heap, 1975; Zavy et al., 1980; Kensinger et al., 1986) and pseudopregnant gilts (Frank et al., 1977; Guthrie \& Rexroad, 1981; Ziecik et al., 1986; Keys, 1987; Geisert et al., 1987; King \& Rajamahendran, 1988). Even though beads containing oestradiol-17 $\beta$ in Expt 1 failed to cause pseudopregnancy in gilts, results from Expt 2 showed that they delayed the decline in plasma progesterone concentrations compared with cholesterol beads. Much evidence supports the hypothesis that oestradiol-17 $\beta$ from intrauterine origin changes PGF- $2 \alpha$ secretion by the uterus, from an endocrine to an exocrine type (Bazer \& Thatcher, 1977). Alternatively, oestradiol-17 $\beta$ could increase the back transfer of PGF-2 $\alpha$ in the mesometrium vasculature (Krzymowski et al., 1990). Results from the present study are partly in accord with both hypotheses, as utero-ovarian vein plasma concentrations of PGF- $2 \alpha$ 
were lower, overall, in gilts treated with beads containing oestradiol-17 $\beta$ than with cholesterol beads.

More PGF-2 $\alpha$ secretory spikes, with a greater amplitude, have been reported for cycling than for pregnant gilts (Moeljono et al., 1977) or gilts treated with oestradiol valerate (Frank et al., 1977). These results were not substantiated in the present experiment, although the average number of peaks tended to be higher in gilts receiving cholesterol beads than in those with beads containing oestradiol-17 $\beta$. However, a fair comparison between the present study and these two reports is hard to make because they both used visual appraisal in determining secretory spikes, and numbers were expressed as a percentage of all samples. Utero-ovarian vein plasma concentrations of PGE-2 and number of secretory spikes were not affected by treatments.

Oestrone concentrations in utero-ovarian vein plasma were lower in oestradiol-17 $\beta+$ PGE-2 than in oestradiol-17 $\beta$ gilts, possibly because of differences in activities of oestrogen sulphotransferase and/or oestrogen sulphatase and suggest an effect of PGE-2 from the beads on the uterine metabolism of oestrogen. Activities of oestrogen sulphotransferase and sulphatase are high and low, respectively, at the beginning of pregnancy in porcine endometrium (Dwyer \& Robertson, 1980), perhaps under the influence of embryonic PGE-2.

The decrease in plasma concentrations of unconjugated oestrogens toward the end of the experimental period reflects the decline in release rate of the beads and does not duplicate the previously mentioned condition to induce pseudopregnancy in gilts, i.e. high plasma oestradiol-17 $\beta$ values at the end of the recognition period. These results apparently explain the incapacity to induce pseudopregnancy in gilts with Silastic beads impregnated with oestradiol-17 $\beta$. Oestrogen measurements in utero-ovarian vein plasma demonstrate that a localized intrauterine application of oestrogens at near-physiological doses can increase the concentrations of unconjugated and sulphoconjugated oestrogens in plasma to values comparable to those in peripheral plasma of gilts in early pregnancy (Robertson \& King, 1974; Robertson et al., 1985). Beads used in the present experiment released enough oestradiol-17 $\beta$ to obtain concentrations in the uterine lumen on Days 15-16 (J. P. Laforest, G. J. King \& T. G. Kennedy, unpublished data) comparable to those obtained previously in pregnant gilts (Keys, 1987). However, the unexpected peak release of oestradiol-17 $\beta$ that followed bead insertion into the uterine lumen resulted in plasma concentrations on Day 11 that were higher than those reported for pregnant gilts (Ford et al., 1982; Robertson et al., 1985; Stone \& Seamark, 1985). Nevertheless, these high concentrations were not maintained for more than 2 days, compared with 6 days with peripheral injections (Frank et al., 1977; Keys, 1987) and, contrary to what was obtained in the present experiment with Silastic beads, little oestrone was measured in the plasma of injected compared with pregnant gilts (Keys, 1987).

High concentrations of oestrone sulphate in plasma until Day 16 showed that the pattern of sulphoconjugated oestrogens in porcine plasma does not reflect the pattern of unconjugated oestrogens. Oestradiol sulphate and oestrone sulphate have been suggested as being responsible for the embryonic effect of oestrogens on maintenance of corpora lutea (Perry et al., 1976), but results of the present experiment do not support this, as concentrations of oestrone sulphate in plasma remained high without initiating pseudopregnancy.

Despite limited lengthening of the cycle, probably caused by a decrease in PGF-2 $\alpha$ in uteroovarian vein plasma in gilts treated with beads containing oestradiol-17 $\beta$, other factors are essential to stimulate maintenance of corpora lutea either directly or through the hypothalamo-pituitaryovarian axis. This missing factor does not seem to be PGE-2 or one of the porcine conceptus secretory proteins (Harney \& Bazer, 1989). Alternatively, since a minimum of four embryos is necessary to maintain pregnancy in pigs (Polge et al., 1966) and elongated conceptuses release oestrogens from all segments (Bate \& King, 1988), PGF-2 $\alpha$ synthesis and release is probably modified throughout most of the uterus during prevention of luteolysis in pregnant animals. Beads may have inhibited endocrine release of PGF- $2 \alpha$ from immediately adjacent regions, but failed to suppress this from distant regions. Hence, lower, but sufficient, PGF-2 $\alpha$ was eventually secreted and so luteolysis occurred. 
The authors wish to express their gratitude to T. G. Kennedy, R. J. Etches, J. I. Raeside and L. A. Guilbault for kindly providing the antisera for prostaglandins, progesterone, oestrone and oestradiol-17 $\beta$, respectively. Thanks are also given to C. Chapeau, D. Wey, C. Anderson-Langmuir and K. L. Laforest for their excellent technical assistance. Financial support was provided by the Natural Sciences and Engineering Research Council of Canada and the Ontario Ministry of Agriculture and Food.

\section{References}

Akinbosotu, B.A., Diehl, J.R. \& Gimenez, T. (1986) Sparing effects of intrauterine treatment with prostaglandin $\mathrm{E}_{2}$ on luteal function in cycling gilts. Prostaglandins 32, 291-299.

Akinlosotu, B.A., Diehl, J.R. \& Gimenez, T. (1988) Prostaglandin $E_{2}$ counteracts the effects of $\mathbf{P G F}_{2 u}$ in indomethacin treated cycling gilts. Prostaglandins 35, $81-93$

Anderson, V.L. \& McLean, R.A. (1974) Design of Experiments, a Realistic Approach, pp. 17-23. Marce! Dekker Inc, NY.

Ash, R.W. \& Heap, R.B. (1975) Oestrogen, progesterone and corticosteroid concentrations in peripheral plasma of sows during pregnancy, parturition, lactation and after weaning. $J$. Endocr. 64, 141-154.

Bate, L.A. \& King, G.J. (1988) Production of oestrone and oestradiol-17 $\beta$ by different regions of the filamentous pig blastocyst. J. Reprod. Fert. 84, 163-169.

Bazer, F.W. \& Thatcher, W.W. (1977) Theory of maternal recognition of pregnancy in swine based on estrogen controlled endocrine versus exocrine secretion of prostaglandin $F_{2 u}$ by the uterine endometrium. Prostaglandins 14, 397-401.

Christian, L.E., Everson, D.D. \& Davis, S.L. (1978) A statistical method for detection of hormone secretory spikes. J. Anim. Sci. 46, 699-706.

Dwyer, R.J. \& Robertson, H.A. (1980) Oestrogen sulphatase and sulphotransferase activities in the endometrium of the sow and ewe during pregnancy. J. Reprod. Fert. 60, 187-191.

Dziuk, P.J. (1985) Effect of migration, distribution and spacing of pig embryos on pregnancy and fetal survival. J. Reprod. Fert. Suppl. 33, 57-63.

Ford, S.P., Magness, R.R., Farley, D.B. \& van Orden, D.E. (1982) Local and systemic effects of intrauterine estradiol-17 $\beta$ on luteal function of nonpregnant sows. J. Anim. Sci. 55, 657-664.

Frank, M., Bazer, F.W., Thatcher, W.W. \& Wilcox, C.J. (1977) A study of prostaglandin $F_{2 a}$ as the luteolysin in swine. III. Effects of estradiol valerate on prostaglandin F, progestins, estrone and estradiol concentrations in the utero-ovarian vein of nonpregnant gilts. Prostaglandins 14, $1183-1196$.

Gardner, M.L., First, N.L. \& Casida, L.E. (1963) Effects of exogenous estrogens on corpus luteum maintenance in gilts. J. Anim. Sci. 22, 132-134.

Geisert, R.D., Brookbank, J.W., Roberts, R.M. \& Bazer, F.W. (1982) Establishment of pregnancy in the pig. II. Cellular remodelling of the porcine blastocyst during elongation of day 12 of pregnancy. Biol. Reprod. 27, 941-955.

Geisert, R.D., Zavy, M.T., Wettemann, R.P. \& Biggers,
B.G. (1987) Length of pseudopregnancy and pattern of uterine protein release as influenced by time and duration of oestrogen administration in the pig. $J$. Reprod. Fert. 79, 163-172.

Godkin, J.D., Bazer, F.W., Lewis, G.S., Geisert, R.D. \& Roberts, R.M. (1982) Synthesis and release of polypeptides by pig conceptuses during the period of blastocyst elongation and attachment. Biol. Reprod. 27, 977-987.

Guilbault, L.A., Roy, G.L., Grasso, F. \& Matton, P. (1988) Influence of pregnancy on the onset of oestrus and luteal function after prostaglandin-induced luteolysis in cattle. J. Reprod. Fert. 84, 461-468.

Guthrie, H.D. \& Rexroad, C.E.J. (1981) Endometrial prostaglandin $\mathbf{F}$ release in vitro and plasma 13 , 14-dihydro-15-keto-prostaglandin $\mathrm{F}_{2 \alpha}$ in pigs with luteolysis blocked by pregnancy, estradiol benzoate or human chorionic gonadotropin. J. Anim. Sci. 52, $330-339$.

Guthrie, H.D., Henricks, D.M. \& Handlin, D.L. (1972) Plasma estrogen, progesterone and luteinizing hormone prior to estrus and during early pregnancy in pigs. Endocrinology 91, 675-679.

Harney, J.P. \& Bazer, F.W. (1989) Effect of porcine conceptus secretory proteins on interestrous interval and uterine secretion of prostaglandins. Biol. Reprod. 41, 277-284.

Henderson, K.M., Scaramuzzi, R.J. \& Baird, D.T. (1977) Simultaneous infusion of $\mathrm{PGE}_{2}$ antagonizes the luteolytic action of $\mathrm{PGF}_{2 u}$ in vivo. J. Endocr. 72, 379-383.

Henricks, D.M., Guthrie, H.D. \& Handlin, D.L. (1972) Plasma estrogen, progesterone and luteinizing hormone levels during the estrous cycle in pigs. Biol. Reprod. 6, 210-218.

Kennedy, T.G. (1979) Prostaglandins and increased endometrial vascular permeability resulting from the application of an artificial stimulus to the uterus of the rat sensitized for the decidual cell reaction. Biol. Reprod. 20, 560-566.

Kensinger, R.S., Collier, R.J., Bazer, F.W. \& Kraeling, R.R. (1986) Effect of number of conceptuses on maternal hormone concentrations in the pig. J. Anim. Sci. 62, 1666-1674.

Keys, J.L. (1987) Structural changes in porcine uterine epithelium during the estrous cycle, early pregnancy and pseudopregnancy. Ph.D. thesis, Guelph University, Guelph, Ontario, Canada.

Keys, J.L. \& King, G.J. (1988) Morphological evidence for increased uterine vascular permeability at the time of embryonic attachment in the pig. Biol. Reprod. 39, 473-487. 
Keys, J.L. \& King, G.J. (1990) Microscopic examination of porcine conceptus-maternal interface between Days 10 and 19 of pregnancy. Am. J. Anat. 188, 221-238.

Keys, J.L. \& King, G.J. Effects of topical and systemic estrogen on morphology of porcine uterine epithelia. Biol. Reprod. (in press).

Kidder, H.E., Casida, L.E. \& Grummer, R.H. (1955) Some effects of estrogen injections on the estrual cycle of gilts. J. Anim. Sci. 14, 470-474.

King, G.J. \& Rajamahendran, R. (1988) Comparison of plasma progesterone profiles in cyclic, pregnant, pseudopregnant and hysterectomized pigs between 8 and 27 days after oestrus. $J$. Endocr. 119, 11 I-I16.

King, G.J., Walton, J.S. \& Bellissimo, D.J. (1985) Anestrus in pigs: confirmation by a solid-phase RIA for progesterone and subsequent response to treatment. Can. vet. J. 26, 2-6.

Krzymowski, T., Kotwica, J. \& Stefanczyk-Krzymowska, S. (1990) Uterine and ovarian countercurrent pathways in the control of ovarian function in the pig. $J$. Reprod. Fert. Suppl. 40, 179-191.

Lewis, G.S. (1989) Prostaglandin secretion by the blastocyst. J. Reprod. Fert. Suppl. 37, 261-267.

Lewis, G.S. \& Waterman, R.A. (1983) Metabolism of arachidonic acid in vitro by porcine blastocysts and endometrium. Prostaglandins 25, 871-880.

Little, T.M. \& Hills, F.J. (1978) In Agricultural Experimentation: Design and Analysis, pp. 331-340. John Wiley \& Sons, NY.

Moeljono, M.P.E., Thatcher, W.W., Bazer, F.W., Frank, M., Owens, L.J. \& Wilcox, C.J. (1977) A study of prostaglandin $F_{2 a}$ as the luteolysin in swine. II. Characterization and comparison of prostaglandin $\mathrm{F}$, estrogens and progestin concentrations in uteroovarian vein plasma of nonpregnant and pregnant gilts. Prostaglandins 14, 543-555.

Montgomery, D.C. (1984) Design and Analysis of Experiments, 2nd edn, pp. 85-122. John Wiley \& Sons, NY.

Parvizi, N., Elsaesser, F., Smidt, D. \& Ellendorff, F. (1976) Plasma luteinizing hormone and progesterone in the adult female pig during the oestrous cycle, late pregnancy and lactation, and after ovariectomy and pentobarbitone treatment. J. Endocr. 69, 193-203.

Perry, J.S., Heap, R.B., Burton, R.D. \& Gadsby, J.E. (1976) Endocrinology of the blastocyst and its role in the establishment of pregnancy. J. Reprod. Fert. Suppl. 25, 85-104.

Perry, J.S. \& Rowlands, I.W. (1962) Early pregnancy in the pig. J. Reprod. Fert. 4, 175-188.

Polge, C., Rowson, L.E.A. \& Chang, M.C. (1966) The effect of reducing the number of embryos during the early stages of gestation on the maintenance of pregnancy in the pig. J. Reprod. Fert. 12, 395-397.

Pope, W.F. \& Stormshak, F. (1981) Involvement of estradiol in intrauterine migration of porcine blastocysts. Biol. Reprod. 24, Suppl. I. abst 183.

Pope, W.F., Maurer, R.R. \& Stormshak, F. (1982) Intrautrine migration of the porcine embryo: influence of estradiol-17 $\beta$ and histamine. Biol. Reprod. 27, 575-579.
Pratt, B.R., Butcher, R.l. \& Inskeep, E.K. (1977) Antiluteolytic effect of the conceptus and of $\mathrm{PGE}_{2}$ in ewes. J. Anim. Sci. 45, 784-791.

Pratt, B.R., Butcher, R.L. \& Inskeep, E.K. (1979) Effect of continuous intrauterine administration of prostaglandin $E_{2}$ on life-span of corpora lutea of nonpregnant ewes. J. Anim. Sci. 48, 1441-1446.

Raeside, J.I. \& Rosskopf, E.M. (1980) Simulation of pregnancy levels of plasma oestrone sulphate by infusion in the non-pregnant mare: a preliminary study. Anim. Reprod. 3, 101-106.

Reynolds, L.P., Robertson, D.A. \& Ford, S.P. (1983) Effects of intrauterine infusion of estradiol-17 $\beta$ and prostaglandin $\mathrm{E}_{2}$ on luteal function in non-pregnant heifers. J. Reprod. Fert. 69, 703-709.

Robertson, H.A. \& King, G.J. (1974) Plasma concentrations of progesterone, estrone, estradiol-17 $\beta$ and of oestrone sulfate in the pig at implantation, during pregnancy and at parturition. $J$. Reprod. Fert. 40, $133-141$.

Robertson, H.A., Dwyer, R.J. \& King, G.J. (1985) Oestrogens in fetal and maternal fluids throughout pregnancy in the pig and comparisons with the ewe and cow. J. Endocr. 106, 355-360.

SAS. User's Guide (1987) SAS Institute Inc. Cary, NC.

Schneider, T.M., Tilton, J.E., Okrasa, S., Jeng, M., Weigl, R. \& Williams, G.L. (1982) Effect of intrauterine infusions of prostaglandin $\mathrm{E}_{2}\left(\mathrm{PGE}_{2}\right)$ on luteal function in non-pregnant gilts. J. Anim. Sci. 55, Suppl. 1, abst 662.

Schneider, T.M., Tilton, J.E., Okrasa, S., Mah, J., Weigl, R. \& Williams, G.L. (1983) The effect of intrauterine infusions of prostaglandin $\mathrm{E}_{2}$ on luteal function in nonpregnant gilts. Theriogenology 20, 509-520.

Snedecor, G.W. \& Cochran, W.G. (1980) Statistical Methods, 7 th edn. Iowa University Press, Ames.

Stabenfeldt, G.H., Akins, E.L., Ewing, L.L. \& Morrissette, M.C. (1969) Peripheral plasma progesterone levels in pigs during the oestrous cycle. $J$. Reprod. Fert. 20, 443-449.

Stone, B.A. \& Seamark, R.F. (1985) Steroid hormones in uterine washings and in plasma of gilts between Days 9 and 15 after oestrus and between Days 9 and 15 after coitus. $J$. Reprod. Fert. 75, 209-221.

Wu, M.C. \& Dziuk, P.J. (1988) Ovarian influence on uterine growth in prepubertal gilts. J. Anim. Sci. 66, 2893-2898.

Wu, M.C., Shin, W.J. \& Dziuk, P.J. (1988) Influence of pig embryos on uterine growth. J. Anim. Sci. 66, 1721-1726.

Zavy, M.T., Bazer, F.W., Thatcher, W.W. \& Wilcox, C.J. (1980) A study of prostaglandin $F_{2 u}$ as the luteolysin in swine. V. Comparison of prostaglandin F, progestins, estrone and estradiol in uterine flushings from pregnant and non-pregnant gilts. Prostaglandins 20, 837-851.

Ziecik, A., Doboszynska, T. \& Dusza, L. (1986) Concentrations of $\mathrm{LH}$, prolactin and progesterone in earlypregnant and oestradiol-treated pigs. Anim. Reprod. Sci. 10, 215-224.

Received 21 December 1990 